\title{
Effects of Haemodialysis on Red Cell Indices and Haematocrit in Chronic Kidney Disease Patients
}

\author{
Mohammed Nasim Uddin Chowdhury ${ }^{1 *}$ \\ Monira Khatun ${ }^{2}$ \\ Pradip Kumar Dutta ${ }^{3}$ \\ Nayeema Akhter ${ }^{4}$ \\ 'Department of Physiology \\ Rangamati Medical College \\ Rangamati, Bangladesh. \\ ${ }^{2}$ Department of Physiology \\ Chittagong Maa-O-Shishu Hospital Medical College \\ Chittagong, Bangladesh.
}

${ }^{3}$ Department of Nephrology Chittagong Medical College Chittagong, Bangladesh.

${ }^{4}$ Department of Physiology Chittagong Medical College Chittagong, Bangladesh

\section{*Correspondence to:}

Dr. Mohammed Nasim Uddin Chowdhury Assistant Professor Department of Physiology Rangamati Medical College Rangamati, Bangladesh.

Mobile : +88 01732060629

E-mail:drnasimuddin@ymail.com

\begin{abstract}
Background: Chronic Kidney Disease (CKD) is an escalating public health problem throughout the developed and developing world. Haemodialysis influences the transport of water through the erythrocyte membrane and induces morphologic and functional modifications. Objective: This study is aimed at to show the effects of haemodialysis on red cell indices and haematocrit in Chronic Kidney Disease (CKD) patients receiving Maintenance Haemodialysis (MHD) during haemodialysis (HD) process in their post-dialysis blood samples. Methods: It is a Hospital based, crosssectional comparative study. The study population consisted of 40 patients of diagnosed case of chronic kidney disease patients on haemodialysis in the Department of Nephrology, Chittagong Medical College Hospital, Chittagong. The haematological changes before and after the ending of haemodialysis procedure were studied by complete blood count study by automated analyzer. Data were analyzed by statistical methods (Paired sample t-test). Results: In our study the predialysis and post-dialysis sample showed the mean $( \pm \mathrm{SD}) \mathrm{MCV}(\mathrm{fl})$ was $96.20( \pm 11.57) f l$ and $92.80( \pm 10.75) f l$ respectively. This shows highly significant difference between mean of pre-dialysis and post-dialysis MCV(fl) level $(\mathrm{p}=0.001)$. In pre-dialysis and post-dialysis sample the mean $( \pm \mathrm{SD}) \mathrm{MCH}(\mathrm{pg})$ was $29.10( \pm 3.62) p g$ and $28.79( \pm 3.77) p g$ respectively. This shows no significant difference between mean of pre-dialysis and post-dialysis $\mathrm{MCH}(\mathrm{pg})$ level $(\mathrm{p}=0.236)$. In pre-dialysis and post-dialysis sample the mean $( \pm \mathrm{SD}) \mathrm{MCHC}(\mathrm{g} / \mathrm{dL})$ was $29.25( \pm 3.69) \mathrm{g} / \mathrm{dL}$ and $30.25( \pm 3.57) \mathrm{gm} / \mathrm{dL}$ respectively. This shows highly significant difference between mean of pre-dialysis and post-dialysis $\mathrm{MCHC}(\mathrm{g} / \mathrm{dL})$ level $(\mathrm{p}=0.003)$. In pre-dialysis and post-dialysis sample the mean $( \pm \mathrm{SD})$ Haematocrit/PCV(\%) was $26.46( \pm 7.34) \%$ and $27.39( \pm 8.07) \%$ respectively. This shows no significant difference between mean of pre-dialysis and post-dialysis Haematocrit/PCV(\%) level ( $\mathrm{P}=0.157)$. Conclusion: The results of this study revealed that significant morphological changes, specially, regarding MCV occurs in patients receiving MHD during HD process in their post-dialysis blood samples along with consequent changes in MCHC. And all these findings are consistent with each other.
\end{abstract}

Key words: Chronic kidney disease; Renal replacement therapy; Haemodialysis; Maintenance haemodialysis; Haematocrit; MCV; MCHC; MCH; PCV.

\section{INTRODUCTION}

Chronic Kidney Disease (CKD) is an escalating public health problem throughout the developed and developing world. CKD carries with it not only a risk for progression to End-Stage Renal Disease (ESRD), but also increased morbidity and mortality, particularly from cardiovascular disease $\mathrm{e}^{1,2,3,4}$. CKD has gained paramount 
importance due to its profound morbidity and mortality. The haematological changes being one of the major contributing factor. Anaemia is an almost invariable consequence of renal failure. Chronic kidney disease leads to a buildup of fluid and waste products in the body. This condition affects most body systems and functions, including red blood cell production, blood pressure control, and vitamin D and bone health ${ }^{5}$.

CKD is a progressive disease which ends at End Stage Renal Disease (ESRD) when patients fail to survive without Renal Replacement Therapy (RRT) either in the form of a dialysis or a transplant ${ }^{6}$. Dialysis involves the removal of urea and other toxic substances from the plasma as well as the correction of electrolyte imbalance ${ }^{7}$.

Haemodialysis generally improves the fluid environment of the erythrocytes by partial correction of the electrolyte disequilibrium, the acid-base status and the removal of a number of uremic substances that may possibly disturb both the biochemical and physical properties of the cells ${ }^{8}$. Considering the nature of the haemodialysis process, it should have a considerable impact on the morphology of the cells ${ }^{8}$. Haemodialysis influences the transport of water through the erythrocytic membrane and induces morphologic and functional modifications 9 .

Investigators showed that the baseline values for plasma osmolality in uremic patients were higher than controls, probably because of the presence of uremic toxins, which may modify erythrocytic deformability and viability ${ }^{9}$. So it can be assumed that RBC may undergo significant morphologic changes in CKD patients by haemodialysis.

Therefore the present study has been designed to observe the effects of haemodialysis on red cell indices and haematocrit in chronic kidney disease patients receiving Maintenance Haemodialysis (MHD) during Haemodialysis (HD) process in their post-dialysis blood samples.

\section{MATERIALS AND METHODS}

The present study was a hospital based, cross-sectional comparative study. The study was conducted in the Department of Nephrology, Chittagong Medical College Hospital, Chittagong in collaboration with the Department of Physiology, Chittagong Medical College, Chittagong between July 2011 to June 2012.

The study population consisted of 40 patients of registered case of CKD on Maintenance Haemodialysis (MHD) in the Department of Nephrology, Chittagong Medical College Hospital, Chittagong were selected as cases by the process of purposive sampling. Inclusion criteria includes patient with chronic kidney disease on MHD in the Chittagong Medical College Hospital during study period with age $>18$ years and $<70$ years providing informed written consent. Patients with acute medical conditions like acute MI, Stroke etc, CKD with other preexisting known diseases like bronchial asthma,
COPD, tuberculosis etc, CKD with $\mathrm{H} / \mathrm{O}$ bleeding disorders eg. haemophilia, purpura, haemolytic anaemia etc, CKD with $\mathrm{H} / \mathrm{O}$ haematemesis, malaena or any other co-morbid medical conditions, CKD with CLD, malignancy were excluded. Ethical clearance was taken properly from the ethical committee of Chittagong Medical College, Chittagong.

From all eligible subjects clinical history had been taken and clinical examination performed. Then, for haematological study, about $3 \mathrm{ml}$ of venous blood were collected following good medical practice with a $5 \mathrm{ml}$ disposable syringe just before and after HD treatment and sent to a selected standard private laboratory in a EDTA tube for Complete Blood Count $(\mathrm{CBC})$ by an automated analyzer (Cell counter). CBC report were collected from the Diagnostic laboratory duly. Data were processed and analyzed using computer based software Statistical Package for Social Sciences (SPSS) v.18.0 for Windows. Different statistical methods like mean, standard deviation and Student's t-test were applied to describe the continuous data and $\mathrm{p}$ value was considered as statistically significant when it was less than 0.05 .

\section{RESULTS}

Table 1 : MCV variation of respondents.

\begin{tabular}{lccccc} 
MCV (fl) & n & Mean & SD & Median & Range \\
Pre-Dialysis & 40 & 96.20 & 11.57 & 97.00 & $66-114$ \\
Post-Dialysis & 40 & 92.80 & 10.75 & 93.50 & $67-111$ \\
\hline
\end{tabular}

- Paired samples T-test statistics : $\mathrm{t}=3.440, \mathrm{p}=0.001$ (Highly significant)

Table 1 shows that in pre-dialysis and post-dialysis sample the mean $( \pm$ SD) MCV(fl) was $96.20( \pm 11.57) f l$ and $92.80( \pm 10.75) f l$ respectively. This shows highly significant difference between mean of pre-dialysis and post-dialysis MCV(fl) level $(\mathrm{p}=0.001)$.

Table 2 : MCH variation of respondents.

\begin{tabular}{llllll} 
MCH $(\mathrm{pg})$ & $\mathbf{n}$ & Mean & SD & Median & Range \\
Pre-Dialysis & 40 & 29.10 & 3.62 & 29.70 & $16.5-34.5$ \\
Post-Dialysis & 40 & 28.79 & 3.77 & 28.50 & $16.7-34.7$ \\
\hline
\end{tabular}

- Paired samples T-test statistics : $\mathrm{t}=1.204, \mathrm{p}=0.236$ (Not significant)

Table 2 shows the $\mathrm{MCH}(\mathrm{pg})$ in pre-dialysis and post-dialysis sample of the patients. In pre-dialysis and post-dialysis sample the mean $( \pm \mathrm{SD}) \mathrm{MCH}(\mathrm{pg})$ was $29.10( \pm 3.62) \mathrm{pg}$ and $28.79( \pm 3.77)$ pg respectively. This shows no significant difference between mean of pre-dialysis and post-dialysis $\mathrm{MCH}(\mathrm{pg})$ level $(\mathrm{p}=0.236)$. 
Table 3 : MCHC variation of respondents.

\begin{tabular}{lllllc} 
MCHC (g/dL) & n & Mean & SD & Median & Range \\
Pre-Dialysis & 40 & 29.25 & 3.69 & 29.95 & $19.1-39.6$ \\
Post-Dialysis & 40 & 30.25 & 3.57 & 30.30 & $19.4-37.4$ \\
\hline
\end{tabular}

- Paired samples T-test statistics : $\mathrm{t}=3.128, \mathrm{p}=0.003$ (Highly significant)

Table 3 shows the $\mathrm{MCHC}(\mathrm{g} / \mathrm{dL})$ in pre-dialysis and postdialysis sample of the patients. In pre-dialysis and post-dialysis sample the mean $( \pm \mathrm{SD}) \mathrm{MCHC}(\mathrm{g} / \mathrm{dL})$ was $29.25( \pm 3.69) \mathrm{g} / \mathrm{dL}$ and $30.25( \pm 3.57) \mathrm{gm} / \mathrm{dL}$ respectively. This shows highly significant difference between mean of pre-dialysis and postdialysis MCHC(g/dL) level ( $\mathrm{p}=0.003)$.

Table 4 : Haematocrit / PCV variation of respondents.

\begin{tabular}{llcccc} 
Haematocrit/PCV(\%) & n & Mean & SD & Median & Range \\
Pre-Dialysis & 40 & 26.46 & 7.34 & 25.60 & $13.8-39.4$ \\
Post-Dialysis & 40 & 27.39 & 8.07 & 26.45 & $14.1-43.2$ \\
\hline
\end{tabular}

- Paired samples T-test statistics : $\mathrm{t}=1.443, \mathrm{p}=0.157$ (Not significant)

Table 4 shows the Haematocrit/PCV (\%) in pre-dialysis and post-dialysis sample of the patients. In pre-dialysis and postdialysis sample the mean $( \pm \mathrm{SD})$ Haematocrit/PCV (\%) was $26.46( \pm 7.34) \%$ and $27.39( \pm 8.07) \%$ respectively. This shows no significant difference between mean of pre-dialysis and postdialysis Haematocrit/PCV (\%) level ( $\mathrm{p}=0.157)$.

\section{DISCUSSION}

This cross-sectional, comparative study had been carried out to observe the effects of haemodialysis on red cell indices and haematocrit in chronic kidney disease patients receiving Maintenance Haemodialysis (MHD) during haemodialysis (HD) process in their post-dialysis blood samples. In our study, in pre-dialysis and post-dialysis sample the mean $( \pm \mathrm{SD})$ MCV(fl) was $96.20( \pm 11.57)$ fl and $92.80( \pm 10.75) f l$ respectively. This shows highly significant difference between mean of predialysis and post-dialysis $\mathrm{MCV}(\mathrm{fl})$ level $(\mathrm{p}=0.001)$. Here MCV is reduced in post-dialysis blood sample. This may be due to intracellular (RBC) fluid volume correction during HD process. Also this finding is consistent with our other findings in this study.
In the study the pre-dialysis and post-dialysis sample showed the mean $( \pm \mathrm{SD}) \mathrm{MCH}(\mathrm{pg})$ was $29.10( \pm 3.62) \mathrm{pg}$ and $28.79( \pm 3.77) p g$ respectively. This shows no significant difference between mean of pre-dialysis and post-dialysis $\mathrm{MCH}(\mathrm{pg})$ level $(\mathrm{p}=0.236)$. We know, total amount of haemoglobin in a particular cell is constant at a particular time. So our result signifies the validity of this fact and vice versa. Again in pre-dialysis and post-dialysis sample the mean $( \pm \mathrm{SD})$ $\mathrm{MCHC}(\mathrm{g} / \mathrm{dL})$ was $29.25( \pm 3.69) \mathrm{g} / \mathrm{dL}$ and $30.25( \pm 3.57) \mathrm{gm} / \mathrm{dL}$ respectively. This shows highly significant difference between mean of pre-dialysis and post-dialysis $\mathrm{MCHC}(\mathrm{g} / \mathrm{dL})$ level $(\mathrm{P}=0.003)$. Here, mean MCHC is more in post-dialysis sample. This may be due to the correction of intracellular (RBC) fluid volume with consequent reduction in $\mathrm{MCV}$. So it is also consistent with our other findings mentioned above.

In our study the pre-dialysis and post-dialysis sample showed the mean $( \pm \mathrm{SD})$ Haematocrit/PCV (\%) was $26.46( \pm 7.34) \%$ and $27.39( \pm 8.07) \%$ respectively. This shows no significant difference between mean of pre-dialysis and post-dialysis Haematocrit/PCV (\%) level $(\mathrm{p}=0.157)$. This may be due to simultaneous correction of both intracellular (RBC) and extracellular (PLASMA) volume overload during HD process so that the ratio between packed cell volume and plasma volume were constant. So it is also consistent with our previous findings.

\section{CONCLUSION}

Chronic kidney disease has evolved as a silent killer if not managed in its early stage. Haemodialysis influences the transport of water through the erythrocyte membrane and induces morphologic and functional modifications. Haemodialysis is one of the most popular form of renal replacement therapy. Considering the nature of haemodialysis processs we designed the present cross-sectional, comparative study to observe the effects of haemodialysis on red cell indices and haematocrit/PCV in chronic kidney disease patients of both sexes and to compare the changes in pre-dialysis and postdialysis blood samples.

In the light of results of this study, it can be concluded that significant changes in $\mathrm{MCV}$ and $\mathrm{MCHC}$ occurs in patients during HD process in their post-dialysis blood samples along with no significant changes in $\mathrm{MCH}$ and haematocrit/PCV and all these findings are consistent with each other.

This study might help to evaluate the effect of HD in chronic kidney disease patient, which seems to cause significant changes in red cell morphology by haemodialysis.

\section{DISCLOSURE}

All the authors declared no competing interest. 


\section{REFERENCES}

1. Foley RN, Parfrey PS. Cardiovascular disease and mortality in ESRD. J Nephrol. 1998; 11(5) :239-245.

2. Weiner DE, Tighiouart H, Vlagopoulos PT, Griffith JL, Salem DN, Levey AS, Sarnak MJ. Effects of anaemia and left ventricular hypertrophy on cardiovascular disease in patients with chronic kidney disease. J Am Soc Nephrol. 2005;16(6):1803-1810.

3. Ma JZ, Ebben J, Xia H, Collins AJ. Haematocrit level and associated mortality in haemodialysis patients. J Am Soc nephrol. 1999;10(3):610619.

4. Khanam S, Begum N, Begum S, Hoque EAM. Changes in haematological indices in different stages of chronic renal failure. J Bangladesh Soc Physiol.2007;(2):38-41.

5. Chronic kidney disease. A.D.A.M. Medical Encyclopedia. Atlanta (GA): A.D.A.M. .2011.

6. Dutta PK, Kashem MA, DAS S, Huda MN, Dutta A. Establishment of a nationwide chronic dialysis programme under public-private partnership. J CMCTA. 2011;22(2):1-65.

7. Mohamed Siddig MA, Muna Abbas B, Leena Babiker M, Fadl Aljabbar ATA, Mekki HA. Haematological changes post-haemo and peritoneal dialysis among renal failure patients in Sudan. Saudi J Kidney Dis Trans. 2008;19(2):274-279.

8. Viljoen M, Willemse, Bower G. Erythrocytes and haemodialysis. Department of Physiology, University of Pretoria.http://www.edoc.co.za/newedoc/modules.php.

9. Buemi M, Floccari F, Pasquale GD, Cutroneo G, Sturiale A, Aloisi C et al. AQP1 in red blood cells of uremic patients during haemodialytic treatment. Nephron. 2002;92(4):846-852. 